\title{
Planning for the global interactive Robson platform in the Eastern Mediterranean Region ${ }^{1}$
}

Citation: Planning for the global interactive Robson platform in the Eastern Mediterranean Region. East Mediterr Health J. 2020;26(2):239-240 https:// doi.org/10.26719/2020.26.2.239

Copyright (c) World Health Organization (WHO) 2020. Open Access. Some rights reserved. This work is available under the CC BY-NC-SA 3.0 IGO license (https://creativecommons.org/licenses/by-nc-sa/3.o/igo).

\section{Introduction}

Improved understanding of caesarean section rates has been hindered by the lack of a consistent, internationally accepted classification system to monitor and compare rates. To address this, the World Health Organization (WHO) proposed the adoption of the Robson classification system (1), designed to facilitate comparison and analysis of caesarean section rates within and between different facilities, and across countries and regions. WHO has also developed an interactive online platform in which facilities worldwide can upload data according to the Robson classification system (2). In this context, the WHO Regional Office for the Eastern Mediterranean held an informal consultative meeting on testing and adopting planning for the global interactive Robson platform in the Eastern Mediterranean Region in Cairo, Egypt, from 4 to 5 September 2019 (3). The meeting was attended by 30 participants from six countries (Egypt, Islamic Republic of Iran, Lebanon, Morocco, Pakistan and Syrian Arab Republic), as well as staff from the United Nations Population Fund (UNFPA) Regional Office for the Arab States and from WHO headquarters, Regional Office and country offices. The objectives of the consultation were to:

- discuss components of the caesarean section global interactive platform newly developed by WHO;

- debate approaches for adopting the use of the caesarean section online platform at the health facility and ministry of health levels; and

- determine the mechanisms needed to ensure caesarean section comparative analysis using caesarean section data collection.

\section{Summary of discussions}

The role of litigation in reducing unnecessary caesarean section was noted, as was the need for training protocols for normal vaginal deliveries and surveillance systems using disaggregated data to monitor the use of caesarean section, and pre-requisites were identified for adopting the Robson classification system, including obstetrics guidelines, clinical review and audits. Good practices in countries were shared, highlighting training components, mapping of caesarean section, operational research, and preparing the health information system for the monitoring and evaluation of caesarean section use, using the Robson classification system. There was consensus on the importance of adopting a standardized approach and having a single platform for all countries for data related to caesarean section to facilitate access to country data and allow comparative analysis and learning exchange.

There was also discussion on the role of the mass media in improving the use of the Robson classification system, and agreement on the importance of sensitizing the public to the benefits of normal vaginal delivery, and of adopting a communication plan to improve the knowledge, attitudes and practices of health care providers and women.

\section{Recommendations}

\section{To WHO}

- Raising the awareness of concerned parties (policy-makers, programme managers and professionals) on the benefits of the Robson classification system and the global online platform for optimizing the use of caesarean section.

- Strengthening and enforcing regulations and policies related to caesarean section and the application of the Robson classification system.

\section{To Member States}

- Involving obstetricians/gynaecologists, midwives and information officers in implementing the Robson classification system global online platform.

- Ensuring training of trainers on the Robson classification system for the public and private sectors and disseminating related guides and tools.

- Establishing caesarean section committees, at the hospital level, to ensure the implementation of the Robson classification system in line with a "quality of care" approach.

- Implementing the Robson classification system online platform, at the hospital level, and ensuring adequate primary and comparative analysis and interpretation of data for appropriate action.

This report is based on the proceedings of the Informal consultative meeting on testing and adopting planning for the global interactive Robson platform in the Eastern Mediterranean Region, 4-5 September 2019, Cairo, Egypt (http://applications.emro.who.int/docs/IMR-WRH-109-2019-EN. df?ua=1). 
- Considering the linkages and possible integration of the platform with other existing digital health information systems .
- Strengthening the response to the high use of caesarean section, including adoption of WHO guidelines on non-clinical interventions to reduce unnecessary caesarean section.

\section{References}

1. World Health Organization. The Robson classification implementation manual. Geneva: World Health Organization; 2017 (https://www.who.int/reproductivehealth/topics/maternal_perinatal/robson-classification-implementation/en/).

2. World Health Organization. A systematic review of the Robson Classification for caesarean section. Geneva: World Health Organization; 2020 (https://www.who.int/reproductivehealth/topics/maternal_perinatal/robson-classification/en/).

3. World Health Organization Regional Office for the Eastern Mediterranean (WHO/EMRO). Informal consultative meeting on testing and adopting planning for the global interactive Robson platform in the Eastern Mediterranean Region. Cairo: WHO/ EMRO; 2019 (http://applications.emro.who.int/docs/IMR-WRH-109-2019-EN.pdf?ua=1). 